\title{
Rethinking and redesigning sustainability in Dubai's Sustainable City
}

\author{
P. Nadali, R. M. Thomas \& H. Taleb \\ Faculty of Engineering and IT, \\ The British University in Dubai, UAE
}

\begin{abstract}
As communities are being developed in Dubai there is an urgent need to consider aspects of sustainability since the country has one of the highest per-capita levels of resource consumption and carbon footprint. The aim of this study is to use an existing project - Dubai's first sustainable city - to analyse it and then rebuild its concepts of sustainability by improving social and environmental dimensions with respect to international standards. The analysis and findings prove that it is essential to adapt sustainability from initial development of the project and enable inhabitants to adapt it as a lifestyle rather than construing it an 'add-on' criterion at a superficial level. Simulation of energy consumption and carbon footprints were carried out to support the research through journal articles.

Keywords: sustainable urban design, urban planning, Dubai Sustainable City, energy performance, carbon footprint, urban densification, urban equity, sustainable suburban development.
\end{abstract}

\section{Introduction}

Social, economic and environmental aspects form the triple bottom line of sustainability and sustainable development. Designing the strategic organisation of buildings, facilities, utilities and public spaces requires a holistic understanding of the various spacial scales within the urban fabric. Another key aspect of any urban development is the manner of movement of people and goods within the city fabric. Creating a polycentric urban configuration allows pedestrian access to the facilities and amenities required for daily living. A clear understanding of the regional and social context is important in designing passive strategies for energy efficient spaces. According to Ritchie and Thomas 
[1], an integrated approach towards city planning is crucial in attaining sustainable environments in terms of buildings, services, transportation, landscaping and so forth.

\section{Methodology}

Information attained from site visits, conversations with project architects and the layout of the existing master plan was analysed to determine any problems that could be rectified and optimised. Based on this, strategies were proposed. Literature reviews and simulations were conducted to support and understand the impact of these strategic developments on site.

\section{Strategies and analysis}

\subsection{Passive design}

An analysis was conducted using IES to test the amount of savings in terms of energy which can be achieved if the building fabric is to be improved. According to Estidama and the Emirates Green Building code, the U-Values for a wall and roof are required to be $0.57 \mathrm{~W} / \mathrm{m}^{2} \mathrm{~K}$ and $0.31 \mathrm{~W} / \mathrm{m}^{2} \mathrm{~K}$ consecutively. However, in the proposed design as indicated in table 1 , the U-values have been improved to the Passivhaus standard of $0.15 \mathrm{~W} / \mathrm{m}^{2} \mathrm{~K}$ for walls and roofs. Optimised construction layers managed to save a total of $35 \%$ in comparison to the base case (the current design of the townhouses). Setting the thermostat at $24^{\circ} \mathrm{C}$ compared to $21^{\circ} \mathrm{C}$ yields a cooling load reduction of $17 \%$. Applying these strategies shows a simulated reduction in the cooling load of $45 \%$.

Table 1: Energy load for cooling.

\begin{tabular}{|c|r|r|r|r|}
\hline & \multicolumn{4}{|c|}{ ROOM COOLING PLANT SENS. IOAD (MWh) } \\
\hline & DASE CASE & $\begin{array}{c}\text { OPTIMISED } \\
\text { CONSTRUCTION }\end{array}$ & $\begin{array}{c}24 \\
\text { DEGREES }\end{array}$ & $\begin{array}{c}\text { OVERALI } \\
\text { OPTIMISED }\end{array}$ \\
\hline Jan & 1.039 & 0.7606 & 0.7387 & 0.6271 \\
\hline Feb & 1.2833 & 0.9183 & 0.9598 & 0.7648 \\
\hline Mar & 1.6635 & 1.1499 & 1.2589 & 0.8918 \\
\hline Apr & 2.2575 & 1.4884 & 1.8082 & 1.2043 \\
\hline May & 3.0583 & 1.9436 & 2.574 & 1.6484 \\
\hline Jun & 3.3345 & 2.0889 & 2.8682 & 1.7983 \\
\hline Jul & 3.6992 & 2.2931 & 3.2209 & 1.9981 \\
\hline Aug & 3.7142 & 2.2896 & 3.2347 & 1.9763 \\
\hline Sep & 3.2745 & 2.038 & 2.81 & 1.7499 \\
\hline Oct & 2.7367 & 1.7622 & 2.2567 & 1.5298 \\
\hline Nov & 1.9288 & 1.3073 & 1.5004 & 1.1306 \\
\hline Dec & 1.261 & 0.9079 & 0.919 & 0.7663 \\
\hline Summed total & 29.2505 & 18.9478 & 24.1496 & 16.0857 \\
\hline \% Reduction & & 35.22 & 17.44 & 45.01 \\
\hline
\end{tabular}


Stacked housing is another option proposed, where the units are stacked as a mid-rise residential unit to reduce the overall footprint. A similar comparative analysis was done using IES. Table 2 illustrates optimised building fabric construction that reduces cooling load by $34.5 \%$, while altering orientation along the east-west axis gives a $6.5 \%$ reduction. Increasing the thermostat to $24^{\circ} \mathrm{C}$ reduces cooling loads by $6.5 \%$. Applying green walls along the east and west facades gave a reduction of $2 \%$ in the cooling loads while ground cooling resulted in a $4 \%$ reduction. Overall, passive strategies applied to this building prototype resulted in a 55\% reduction in the cooling load. These results restate the importance of creating bioclimatic design strategies in achieving sustainable energy consumption within the built environment.

Table 2: Detailed energy load for cooling.

\begin{tabular}{|c|c|c|c|c|c|c|c|}
\hline \multirow[t]{2}{*}{ DATE } & \multicolumn{7}{|c|}{ ROOM COOLING PLANT SENS. LOAD (MNW) } \\
\hline & BASE CASE & $\begin{array}{l}\text { OPTMIISED } \\
\text { ORIENTATION }\end{array}$ & $\begin{array}{c}\text { OPTIMISED } \\
\text { CONSTRUCTION }\end{array}$ & GREEN WALL & $\begin{array}{l}\text { GROUND } \\
\text { COOLING }\end{array}$ & 24 DEGREES & $\begin{array}{l}\text { OVERALL } \\
\text { OPTMIISED }\end{array}$ \\
\hline $\mathrm{Jan}$ & 12.80 & 15.94 & 10.05 & 13.11 & 10.59 & 15.94 & 3.8663 \\
\hline Feb & 23.05 & 19.24 & 16.97 & 22.68 & 22.13 & 19.24 & 4.4802 \\
\hline Mar & 39.87 & 33.29 & 28.22 & 39.14 & 39.61 & 33.29 & 12.387 \\
\hline Apr & 67.06 & 59.93 & 45.47 & 65.69 & 66.90 & 59.93 & 28.5966 \\
\hline May & 101.19 & 91.33 & 66.90 & 98.67 & 100.15 & 91.33 & 47.0665 \\
\hline Jun & 113.76 & 103.79 & 74.15 & 111.17 & 111.42 & 103.79 & 54.3074 \\
\hline Jul & 128.67 & 120.14 & 82.68 & 125.50 & 124.76 & 120.14 & 63.3689 \\
\hline Aug & 129.53 & 121.73 & 82.27 & 126.51 & $124.3 \hat{3}$ & $121.7 \hat{\jmath}$ & 63.4141 \\
\hline Sep & 109.49 & 102.75 & 69.01 & 107.01 & 103.79 & 102.75 & 51.3015 \\
\hline Oct & 84.49 & 79.23 & 53.69 & 82.89 & 78.74 & 79.23 & 36.4504 \\
\hline Nor & 52.85 & 53.03 & 34.54 & 52.15 & 48.13 & 53.03 & 22.2771 \\
\hline Dec & 24.99 & 29.32 & 17.50 & 25.05 & 21.56 & 29.32 & 10.4237 \\
\hline Summed total & 887.73 & 829.72 & 581.46 & 869.58 & 852.14 & 829.72 & 397.9398 \\
\hline$\%$ Reduction & & 6.53 & 34.50 & 2.05 & 4.01 & 6.53 & 55.17 \\
\hline
\end{tabular}

\subsection{Sustainable transport}

Excessive automobile usage is one of the main causes of pollution and $\mathrm{CO}_{2}$ emission. Haque et al. [2] argue that it affects urban land and resource use, health and safety, congestion and time wastage and noise pollution. Achieving sustainable transport is done in three ways; first by providing facilities and amenities within walking distance so as to reduce the number of vehicle trips; second, by providing alternate modes of transport and finally by encouraging the use of low emission vehicles. However, Ritchie and Thomas [1] mention that when considering LEVs, although emissions are low, one still has to consider the emissions and costs of manufacturing these vehicles in the first place into account. Promoting the first two alternatives will allow long term sustainability of the site. Creating a well-connected community (both internally and externally to the city's urban fabric) is crucial to better accessibility as well as economic, 
social and environmental benefits. Haque et al. [2] discuss the need for modern transit systems that incorporate sustainable, safe and smart solutions to achieve long-term benefits. Sustainable solutions in terms of economic feasibility, environmental resource efficiency and social equity build on the core paradigms of sustainability. Road safety is a crucial aspect as the number of road fatalities keeps increasing. Efficient planning and land use strategies coupled with strict regulations and education programmes can help tackle this issue and create a safe transportation environment.

\subsubsection{Pedestrian friendly}

Simulations using CityCAD software show an increase in the liveability of the proposed master plan. Allowing pedestrian access throughout the site and positioning basic facilities such as schools and offices within a five minute walking radius allows easy accessibility and reduces the need for vehicular transport. Being a mixed-use community, most the basic facilities can be easily accommodated within the community site, reducing the number of car trips from the community. Having retail space on the ground floor with optimum glazing allows visual interaction with pedestrians. Cafes with outdoor seating further enrich and activate the streetscape. The hierarchy of the streets allows safe access for all users. Vehicular and bus routes are accommodated on a ring road around the site, while dedicated bicycle and buggy tracks allow safe movement for pedestrians. At junctions on the site, signal lights and clear signage can improve bicycle, buggy and pedestrian safety. Changing the materiality of the streets near junctions will also help warn users. Furthermore, the streets need to be well lit to allow safety and security. Automated systems, similar to building management systems, can be integrated throughout to respond to changing conditions on site. This would allow efficient management and use of resources.

\subsubsection{Bicycle friendly}

To encourage bicycle usage within the community dedicated bicycle tracks have been integrated to facilitate safety for bicycle users as well as pedestrians. Covered bicycle storage facilities will be accommodated near residential areas with each residential unit having access to at least one bicycle storage space. This can easily be facilitated in the underground car park facility or even in pocket parks adjacent to the residential spaces. Due the harsh regional climatic conditions during the summer months, tree lined paths allow shaded bicycle and pedestrian transit throughout the site. Furthermore, cyclists will have access to shower and changing rooms in the mixed-use facilities. This will also encourage cyclists from outside the community to reduce their use of automobiles. Such measures encourage non-vehicular access to surrounding communities and improve the economic, social and environmental viability of the site.

\subsubsection{Vehicular access}

Car parking facilities are provided underground for the residential areas with a minimum of one space per residential unit. Two parking zones are provided on either side of the site to accommodate external users of the space. Since the amenities are spaced close together, this parking facility can cater for all 
the spaces, thereby reducing the sprawl of parking spaces. Using permeable or semi permeable materials for the parking lots can reduce the heat island effect and also reduce storm water runoff. Although rainwater is not abundant in this desert region, the region has experienced flooding of streets when it does rain. Furthermore, bus stops are also located within the car park areas thereby promoting transit meeting points that connect various modes of transport. Bicycle storage is also integrated near these stops to allow cyclists easy access to the public transport. The 'Dubai 2020 Urban Masterplan' released by the Dubai Government has a focus on transit oriented design and with the proposed 'Pink Line' of the Metro to be developed along the front main road of the site, integrating a multi-modal transport system will encourage the use of alternative transport options. Also, since the density of the site has been increased, this will encourage public buses to move through the site. The 'Wojhati' initiative by the Dubai Road and Transport Authority allows users to plan travel to their destination allowing real time information to be accessed by users leading to efficient travel.

\subsection{Increase density}

To improve the social equity of the community population density has been increased by increasing housing availability on site. This will result in lowering the area per person on a community level. To reduce the feeling of 'crowding' in the community, various open spaces have been created on site. Increasing density will improve the social and economic viability of the community. In the proposed case, the number of residential units has been increased while the building footprint has been dramatically reduced. This allows for the possibility of future growth within the community as well as providing more land for amenities that could become economically feasible at a later stage. This will also encourage residents of neighbouring communities to engage in social and commercial activities provided on the site. Comparing the existing buildings on site and the proposed design, on average there is a two-fold increase in population density.

\subsection{Reducing built-up areas and increasing landscaping}

Using the CityCAD software, a comparison was done investigating the building footprint and green space of the master plan. The sprawl of residential units in the existing layout is reduced by $27.5 \%$ in the proposed design while green space increases by $58.6 \%$. This includes a series of pocket parks, a major park and playgrounds on the site. Urban landscapes improve the micro-climate of a space, improve the health and quality of life of nearby inhabitants, increase property values through access to open space and improve the biodiversity and ecosystem of the region. Vegetation absorbs carbon dioxide in the atmosphere and binds air pollutants thereby acting as a filtering element to improve air quality and reduce noise pollution. It helps to reduce ambient temperatures, reducing the heat island effect and enables the retention and filtering of storm water, as stated by Ritchie and Thomas [1]. In a desert region with restricted water supplies, efficient 
landscaping elements are crucial in limiting resource consumption. Using native plants and efficient irrigation techniques allows water-efficient landscapes to be achieved on the site. Xeriscaping allows reduced water consumption and improved microclimatic conditions. Moreover, Chow and Brazel [3] suggest that a broad canopy xerophytic allows mitigation of the head island effect while maintaining water-efficient irrigation. Use of micro-irrigation changes the water requirement from gallons per minute to gallons per hour, with a fifty to eighty per cent reduction in irrigation water consumption. Turf grass utilises almost eighty per cent of water supplies thereby deeming it the least efficient landscaping feature. Hart [4] states that an efficient irrigation systems such as drip irrigation allow water to percolate to the plant roots as opposed to spray systems that shower water resulting in a fine mist. In the existing design, green space is landscaped with lawns and vegetation. The more sustainable alternative of xeriscaping is proposed in these areas. Native plants such as date palms and neem trees require less water and at the same time shade a wide radius. Options like this would allow efficient water allocation and usage throughout the site. However, in order to achieve biodiversity, it is also crucial to have a mix of plants in terms of species, sizes and colours.

\subsection{Improving social equity}

Market research in the region has showed that almost fifty per cent of the population can only pay between AED 32,500 and AED 54,000 annually for rent, creating a deficit of affordable housing options in the region. Based on international standards, a basis for affordable housing is when the rents are within thirty per cent of the gross income of a family. The study also showed that there was at least a thirteen per cent gap between the supply and demand of affordable housing units, making it highly feasible for developers in the region to address the issue and attain beneficial returns on investment. At the moment, people working in Dubai often choose to reside in the neighbouring emirates, such as Sharjah and Ajman, due to housing affordability, causing huge congestion on the main highways at peak times according to Sophia [5]. In order to improve social sustainability, it is acknowledged that there should be a wide spectrum of inhabitants living in one neighbourhood. A mixed-income population therefore became one of the aims of the project. Primarily, the 500 townhouses are divided into three types, these are; three bedroom, four bedroom and four bedroom garden villas with differences in area from 50 sq. $\mathrm{m}$ to $150 \mathrm{sq}$. $\mathrm{m}$. However, the number of dwellers per unit does not vary as much as the floor area does. The proposed design aims to deliver five types of housing including a stand-alone townhouse similar to the current design. The house types are: a studio of 37 sq. m, a one bedroom apartment of 85 sq. m, a two bedroom apartment of 134 sq. m, a three bedroom apartment of 171 sq. m, a duplex apartment of 342 sq. $\mathrm{m}$ and villas of 410 sq. $\mathrm{m}$. 


\subsection{Water management}

The primary aim of water demand management is to reduce the consumption of potable water by raising awareness in consumers of sustainable water consumption practices. Furthermore, Wills et al. [6] argue that using water-efficient devices and adopting a responsible attitude towards water consumption impacts greatly on the usage of this limited resource. A study conducted shows that efficient water use attitudes could generate savings of between eighteen and fifty three per cent within the study sample. This involves using water-efficient machines and fixtures, running machines with a full load, not leaving taps running while rinsing dishes or vegetables, all initiatives to reduce water consumption (Willis et al. [6]). Water efficient fixtures and fittings can be incorporated within building codes and regulations for the site thereby ensuring economies of scale as regards the long term sustainability of the site. Water efficiency also reduces carbon emissions as water is often processed in desalination plants. Different pricing strategies that incorporate seasonal variations could improve water consumption as there are increased costs involved. The Abu Dhabi government has launched the 'water-wise' initiative to encourage users to reduce water consumption by creating red and green consumption levels; green is ideal and red is overconsumption. Incorporating these initiatives within communities could enable people to become more 'water-wise'.

\subsection{On-site food production}

Creating self-sustaining cities that are able to produce food locally is becoming a crucial factor in establishing sustainability, offsetting anticipated global food shortages, improving the local economy and providing health benefits, Grewal and Grewal [7]. The logistics of importing food from external sources increases carbon emissions, and costs, while also having a negative impact on the freshness of the produce. A study conducted in North America by Rydin et al. [8] compares three scenarios wherein varying areas of vacant lots, a combination of a vacant lot and residential area and a third scenario combining the second option with the rooftops of industrial and commercial buildings are used to generate the food requirements for the region. The type of agricultural methods - conventional, intensive or hydroponics - control of climatic conditions, seasonal produce and the area allocated for gardening are key determinants. In conclusion, Rydin et al. [8] state that the study revealed that regional savings of $\$ 29 \mathrm{M}$ to $\$ 115 \mathrm{M}$ could be generated depending on the area and method of selfsustenance employed. It discusses the feasibility of $100 \mathrm{~m}^{2}$ plots that, in optimum climatic conditions, can help provide the basic food - fruit and vegetables required by a family. Analysis of an urban agriculture initiative in Detroit shows that better health, new employment opportunities, skills and economies are generated. Furthermore, Rydin et al. [8] suggest that wastewater treatment and management systems on residential sites can be interlinked with gardening initiatives and provide alternatives for fertilizers. In 2014, the Dubai Municipality introduced the 'Grow Your Food' campaign to encourage residents 
to use their balconies or gardens to generate food production. On-site food production via greenhouses and private villa gardens will develop a selfsustaining community and also generate revenue for the community as visitors can also purchase produce. The greenhouse will facilitate a communitysupported agriculture programme where community members will actively participate in food production, making the space socially interactive. CityCAD analysis shows the average distance from residential spaces to the greenhouse is approximately $490 \mathrm{~m}$ and it is within a ten minute walking radius for the residents. Facilitating a farmer's market adjacent to the greenhouse will further improve the quality of the products offered on site as well as generating revenues for the community.

\section{Conclusion}

The aim of this study was to identify areas in which there had not been enough justification of whether or not the current project of a 'Sustainable City' was truly sustainable with regard to the social, economic and environment. Improvements have been made to the proposed plan, in order to further enhance the efficiency of the community as a whole on different scales. In terms of a reduction in overall energy consumption and $\mathrm{CO}_{2}$ emissions, tables and simulations highlight a notable difference between the existing plan of the Sustainable City and the proposed one. Turning to the environmental aspect, a design strategy of reducing the footprint is implemented, resulting in a newer type of housing. By doing so, more area is allocated for xeriscaping and landscaping to further provide more space for the public to interact and eventually to reduce the heat island effect on the site. A Transportation hierarchy has been implemented on site to improve accessibility within the site and to external surroundings in a safe and secure manner. Considerations of increasing density on site and improving the overall social equity of the space has also been analysed. Waste management and water management systems on site have also been discussed in order to improve the overall sustainability of the community in the long term. Integrating renewable energy sources was tested through various permutations of clean energy output. Although sustainable urban design is a vast umbrella of considerations and trade-offs, the authors have attempted to analyse and implement some of the strategies and ideas that could improve liveability and reduce the environmental impact of the site.

\section{Acknowledgement}

The authors would like to thank "MUSTADAMA Ltd. Sustainable Solutions" in Masdar City-Abu Dhabi for sponsoring this paper to be presented in the "Sustainable Development and Planning Conference" held in Istanbul in May 2015. 


\section{References}

[1] Ritchie, A. \& Thomas, R., Sustainable Urban Design: An Environmental Approach. London: Taylor \& Francis, pp. 91-94, 2008.

[2] Haque, M. M., Chin, H. C., \& Debnath, A. K., Sustainable, safe, smart three key elements of Singapore's evolving transport policies. Transport Policy, 27, pp. 20-31, 2013.

[3] Chow, W. T., \& Brazel, A. J., Assessing xeriscaping as a sustainable heat island mitigation approach for a desert city. Building and Environment, 47, pp. 170-181, 2012.

[4] Hart, E., Xeriscaping provides lush landscapes with little water; Art of tree relocation saves dollars and the environment. The American City \& County, 108(1), p. 66, 1993.

[5] Sophia, M. Developers Missing Out On Dubai's Affordable Housing Market-Study, Online. http://gulfbusiness.com/2014/11/developers-missingdubais-affordable-housing-market-study/\#.VLTP7CuUdtw

[6] Willis, R. M., Stewart, R. A., Panuwatwanich, K., Williams, P. R., \& Hollingsworth, A. L., Quantifying the influence of environmental and water conservation attitudes on household end use water consumption. Journal of Environmental Management, 92(8), pp. 1996-2009, 2011.

[7] Grewal, P. S., \& Grewal, P. S., Can cities become self-reliant in energy? A technological scenario analysis for Cleveland, Ohio. Cities, 31, pp. 404-411, 2013.

[8] Rydin, Y., Bleahu, A., Davies, M., Dávila, J. D., Friel, S., De Grandis, G., ... \& Wilson, J., Shaping cities for health: complexity and the planning of urban environments in the 21st century. Lancet, 379 (9831), 2012. 